\section{Hazards of the passive voice}

SiR - Simon Leather (Nature 381, 467; 1996) blames every vice from colloquialism to fabrication in scientific writing on the decline in use of the passive voice. He also suggests that "use of the passive voice encourages precision...".

Perhaps he should also note that only the passive voice can engender a classic grammatical howler: the dependent clause with misattributed subject, as in "by standing at a distance, an unbiased viewpoint is much more likely to be reached ".

\section{Clifford J. Jolly}

Department of Anthropology,

New York University,

New York, New York 10003, USA

SIR - Leather prefers the passive to the active voice, which he even thinks is partly responsible for the increase in fraud over the past 20 years. I think he is, quite simply, mistaken. He is certainly in a minority. Few authors of books on English usage or scientific style manuals prefer the passive.

Leather believes the passive allows researchers to stand at a distance from their work, but scientists cannot help but become involved in their work. Investigators must also not be allowed to stand back and disclaim responsibility. Leather says that only the passive voice demands correct tenses, but good writing, whether in the active or passive, demands correct tenses. Authors may "show no consistency of use", but that is not because they write in the active; it is because they can't write well.

Whatever has led to the increase in scientific fraud - if indeed there has been an increase rather than an increased awareness of fraud - is it likely that the active voice has been an important factor? Pressure to publish and pressure to keep one's job are surely likelier causes. And even 40 years ago papers were written in the active voice: "We wish to suggest a structure for the salt of deoxyribose nucleic acid" (J. D. Watson \& F. H. C. Crick Nature 171, 737-738; 1953).

The heart of the matter is that a good writer knows when to use the active and when to use the passive. When Leather writes that, "as used by many of its adherents, [the active] does no favours to the English language or science", he is really just repeating what he said in his first paragraph, and what is undeniably true. The current generation of science graduates has been let down badly by their education (an expression better in the passive) and many cannot write clear English, whether in the active or in the passive.

\section{Neville W. Goodman}

Department of Anaesthetics,

Southmeads Hospital,

Bristol BS10 5NB, UK

SIR - Leather correctly points out that the active voice can impart a personal agency where none were better shown. But so too the passive voice can hide an agent inappropriately, as in the ever-so-blameless "mistakes were made". Active and passive voices differ not only in whether they name the agent but also in where they position parts of a sentence. Thus, in an essay about "great discoveries", one writes "Great discoveries are published by Nature". But in an essay about the journal, that sentence becomes "Nature publishes great discoveries".

Where subjects and objects are put in a sentence determines in part how coherently individual sentences flow together to form a paragraph. Active and passive voices each have important roles in writing. The clear and graceful writer ignores injunctions against the active or passive voice, and instead chooses an appropriate voice for every sentence.

Tobias I. Baskin

Biology Department,

109 Tucker Hall,

University of Missouri,

Columbia, Missouri 65211 USA

e-mail: Baskin@biosci.mbp.missouri.edu

\section{Is the Pope an alien?}

SIR - Amos addressed the interesting question of chance results and their proliferation $^{1}$ which was later discussed by others ${ }^{2-4}$. In this context, we want to draw attention to a more fundamental problem of statistical inference.

Aristotle investigated situations in which conclusions can be derived from premises. A well known example is that from the two premises (1) all humans are mortal, and (2) Socrates is human, it can be concluded (3) therefore Socrates is mortal. A necessary prerequisite for the validity of this type of syllogistic reasoning is that the premises are absolutely sure. Absolute certainty, however, is not the subject of statistics.

This reasoning becomes invalid when applied to probabilistic premises. If, for example, we randomly pick a human being, the probability that it is the Holy Father is extremely low - it is $1: 6$ billion = 0.00000000017 . Therefore (1) if an individual is human, it is probably not the Pope $(P<0.00000000017)$; (2) John Paul II is the Pope; (3) therefore, he is not a human being $(P<0.00000000017)$. Which is obviously not sensible.

This example proves that the change from absolute certainty to probability makes the syllogistic reasoning false. Unfortunately, this is formally exactly the procedure that is applied in statistical hypothesis testing: (1) if the null hypothesis is true, these data are unlikely $(P<0.05) ;(2)$ the data have occurred; (3) therefore the null hypothesis is wrong $(P<0.05)$.

That this type of inference is wrong was noticed by Aristotle more than 2,000 years ago. It has also been sporadically discussed in the literature for several decades ${ }^{5}$. Nevertheless, this fallacy is still in use, probably because no alternatives are available. Does anybody know a way out of this dilemma?

Hans-Peter Beck-Bornholdt

Hans-Hermann Dubben

University of Hamburg,

Martinistrasse 52 ,

20246 Hamburg, Germany.

1. Amos, B. Nature 379, 484 (1996)

2. Bulstrode, C. Nature $\mathbf{3 7 9}, 765$ (1996).

3. Dunthorn, D. Nature 380, 477 (1996).

4. West, R. Nature 380, 477 (1996).

5. Cohen J. Am. Psychologist 49 ,997-1003 (1994).

\section{Barbaric century?}

SIR - As a scientist whose life almost spans the twentieth century, I believe I have a right to comment on the letter from John Evans (Nature 381, 362; 1996).

$\mathrm{He}$ believes that future historians will consider the twentieth century as "quite the most barbaric in all history". He claims that the two major wars were in part due to scientific ideas and the ready willingness of scientists to devise lethal weapons. He also thinks that scientists seek an undeserved status. Future historians may rate the global eradication of smallpox an ' $\mathrm{A}$ ', the overgrowth of population an ' $\mathrm{F}$ '.

There was less involvement of scientists in the First World War than in the Second. I gave my five best years (34 to 39) to assist the Allies because I thought that three dictatorial regimes were seeking to gain control of vast areas of land and large numbers of people in a very cruel way, by military might. Scientists in the United Kingdom and the United States did have some effect and probably saved many lives. Among the "lethal weapons" that I helped to develop was radar, now found in all commercial ships, aircraft, airports and weather stations.

An important component of science is experiment. I am an experimentalist. I do not see "abstract impersonal logic" in the observation that a mould generates an antibacterial agent. Nor that the track of a particle in a magnetic field curves oppositely to that of an electron.

I qualify as one of the "molecular biologists who go to church". I do so for my own reasons. Among those reasons is no desire to deny or modify the knowledge gained by the careful study of nature. Together with Lord Rayleigh I consider this knowledge to be revelation of the works of a supreme being. I pay them respect and in doing so pay respect to the supreme being. I consider this to be wise.

\section{Ernest Pollard}

5 Chatfield Road,

Niton,

Isle of Wight P038 2DR, UK 